\title{
The influence of assessment on learning motivation
}

\author{
Nadezhda Efremova*, Svetlana Shvedova, Anastasia Huseynova \\ Don State Technical University, Rostov-on-Don, Russia
}

\begin{abstract}
Annotation. This paper considers methodological approaches to the assessment of learning achievement, analysing the impact of the mark on learning motivation of students. External testing and subsequent questionnaires data may serve as an indicator of increasing learning motivation of students due to their confidence in the assessment results. Reliability of assessment is an incentive to enhance learning activities of students and increase interest in a given academic discipline. We observed difficulties of obtaining an objective assessment in schools and possible ways of overcoming them. The research provides the basic provisions of the assessment using the design pattern of assessment tools and processes on the basis of evidence-based arguments modelled on Evidence Centered Design which provides assistance in the development of high-quality assessment tools. The use of patterns may allow educators to make greater use of methods for classifying, organising and planning the assessment of cognitive and competency-based learning outcomes.
\end{abstract}

Assessment of learning achievements plays an important role in the learning process, making the education system and its participants responsible for the results of learning activities, as well as representing the basis for management decision-making and systemic changes in teaching methods. This is especially important in a situation of instability and uncertainty taking into account undergoing processes in society. Therefore, it is necessary to prepare a person for such living conditions about which we know only that they will be different from the existing ones. Motivation to learn, which guides students on the way forward, is essential to achieve these goals. This fundamental characteristic of a person is the basis of productive activity, self-development and the desire for success; it will allow a person to successfully adapt to new living conditions.

For the first time the word "motivation" was used in the early 20th century by A. Schopenhauer in his article "On the Fourfold of the Principle of Sufficient Reason". In the 1930s G. Murray [1] introduced the concept of "achievement motive" and D. McClelland [2] divided all the needs of the highest levels of the human psyche into three main groups: the needs for power, achievement and affiliation. The achievement motive, in his opinion, is a by-product of more fundamental social motives which were always a subject of a study of scientists and practitioners, teachers and philosophers, cultural and political scientists, psychologists and sociologists. The works of J. Adams [3], A. Anastasi [4], B. G. Ananyev

\footnotetext{
* Corresponding author: nefremova61@,dstu.edu.ru
} 
[5], B. Weiner [6], B. Mandel [7], A. K. Markova [8], E. Skinner [9], H. Heckhausen [10], V. D. Shadrikov [11] and others are devoted to the study of the nature of learning motivation. They suggested various methods of formation and development of educational motivation including those ones which deal with development of mechanisms of introspection and self-assessment. According to J. Biggs [12] in a well-organised educational process continuous support for students should be provided by teaching methods, learning activities and achievement assessment system. The key prerequisite for creating reliable feedback, introspection, self-assessment and stimulation of learning activities is knowledge of learning outcomes. Self-control becomes the most important result of a person's readiness for learning activities, and stimulation of creative, rational and emotional aspects is a necessary component of quality learning.

As practice shows, not all kinds of assessment can increase motivation. Dissatisfaction with the mark, and most importantly, lack of understanding of its content cause negative emotions and decreasing interest in learning. Only such an assessment which provides reliable information about the actual level of training and provides the opportunity to see the achievements, find mistakes and understand what needs to be done for further success may have a positive impact [13]. It is the receipt of objective learning results that represents a prerequisite for self-assessment, and self-analysis increases the motivation for further knowledge acquisition and personal development. In turn, the system of acquired knowledge affects the level of motivation, vital interests and needs, views and beliefs, world outlook of an individual [14]. Latent processes of self-assessment, self-correction, self-expression and goal-setting are manifested as an aspect of personal development.

Despite the importance of objective results, the education system is still dominated by the traditional practice of educational assessment, which is not evidence-based and does not use proven and standardized assessment materials. The results of such assessments do not usually inspire confidence of students and do not provide a positive impact on educational motivation. The reason for this is that obtaining an authentic assessment that provides an analysis of the current level of learning and deviations from the required level is quite a difficult task due to the lack of a unified conceptual and methodological understanding of the problems and possibilities of assessment, the shortage of qualified personnel capable of developing reliable assessment tools and using modern assessment methods [15]. At the same time, assessment and monitoring should be aimed at identifying the actual level of students' preparedness in the subject area and while determining competencies. The organization of assessment activities in order to develop conceptual and technological tools and focus on innovative approaches to the development of assessment materials, their standardization and automated processing of results can lead to a significant increase in the efficiency of the educational process. At the same time, it is important to take into account the fundamental requirements: the quality of educational achievements should be measurable and correspond to the stage of training process; the results should be expressed quantitatively on the scale of measurement, they should be available and open for discussion in order to identify problem areas.

It should be considered that it is important for students to gain experience in working with tests independently from the school. Experience shows that students who have prior experience of standardized testing achieve much more successful results in the final certification. According to psychologist A. Anastasi, the results of experienced students are $11 \%$ higher than the results of those who have no experience of working with tests. This is mainly due to the fact that testing becomes similar to any other type of control, and this relieves tension and gives confidence while working with test tasks.

Over the last decade, a number of professional centres for the evaluation of educational achievements, which serve the interests of teachers and students, have appeared in Russia. They create conditions for reliable assessment by means of evidence-based development of 
assessment tools, strict implementation of assessment procedures and automated processing of assessment materials providing prompt and detailed analysis of the results. In one of these centres we conducted an external assessment of level of knowledge in social sciences among 10th grade students in a rural school by means of the standardized testing. The analysis of data has shown that the assessment tools used there complied with the stage of learning process and properly differentiated test subjects by their level of training. Test results on a five-point scale: $3 \%$ - excellent, $56 \%$ - good, 35\% - satisfactory; $94 \%$ of the students passed the test successfully. The probability range of performing the test tasks ranged from 0.992 for the easiest to 0.026 for the most difficult. The central tendency of students' preparedness and task complexity has shown high matching rates. The reliability coefficient obtained on the basis of the average value of the correlation coefficient is 0.75 .

Our concern was to figure out what impact the results of such testing had on the learning motivation of students. Once the results had been obtained and analysed a survey on a wide range of issues was conducted among schoolchildren, teachers and parents. 34 students, 17 teachers and 34 parents took part in the survey. The majority of pupils noted the increase of learning motivation after participation in external testing (Fig. 1). This was also confirmed by their parents and teachers.

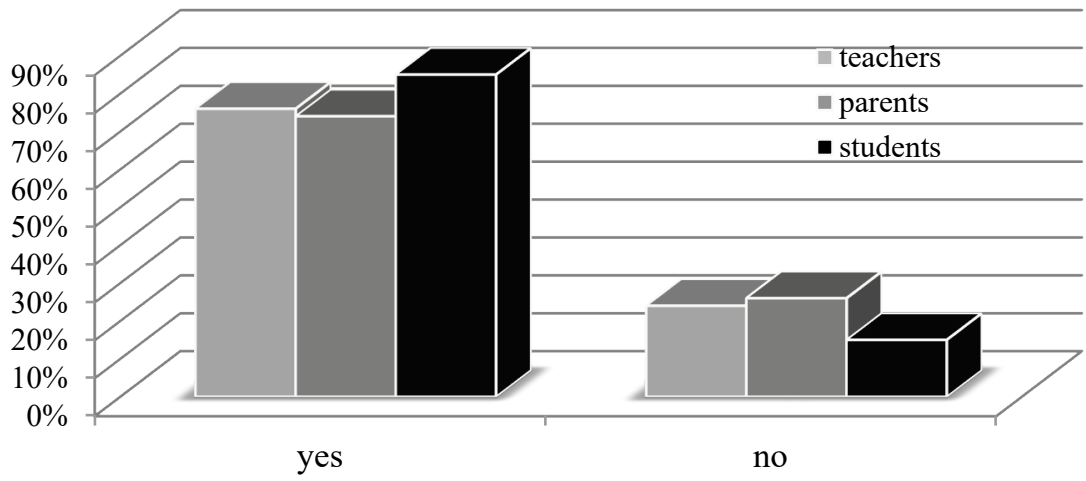

Fig. 1. The assessment of the test results impact on learning motivation.

According to students, the increase in interest in a subject is primarily due to their confidence in the assessment, as well as due to the prompt receipt of information about their achievements and the possibility of comparing them with statistical norms and the results of other participants. An objective assessment allowed each test participant to identify their level of training, and a comparative analysis of the results allowed to mobilize the available opportunities to obtain higher ratings. In the process of the test results analysis value-semantic attitude to learning changes on a personal level. Participation in standardized testing contributes to the acquisition of experience in working with tests, confidence in the possibility of performing a larger number of tasks with the correct allocation of time and the correct strategy of performing the tasks. It should be noted that in this case both students and teachers received and analysed quantitative information of the same attribute for the whole sample of test subjects.

Due to this kind of assessment teachers in a short period of time got detailed information on the whole group of students as well as each student individually within a wide range of controlled elements of content. Therefore, they had more time to analyse the results together with the students which allowed them to strengthen the personal responsibility of each student for the result of training. The impact on teachers is also manifested in the improvement of their qualimetric functions, the review of the role of control in education, the development of objective criteria for evaluating their own work, the need to improve educational technologies. 
Thus, the reliable assessment procedure itself represents a developing and motivating component; it can be considered as an educational technology which should take its place in the learning process as complementary to traditional forms without replacing or excluding them. A number of principles for the organization and conduct of such monitoring should be taken into account: frequency of assessment and its significance; compliance with the sequence and continuity of controlled elements of content; multistaging - assessment - self-assessment, addressing the shortcomings. Standardization of assessment materials and the unity of assessment and processing technologies for all test subjects provide necessary conditions for comparability of data and availability of information for analysis and discussion. The quality of educational measurement is of particular importance. It is difficult to ensure this in school practice as the development of assessment tools is quite labour-intensive and requires a certain degree of expertise. Therefore, there is a need to turn to professional centers or using so-called design patterns for assessment tools.

An effective way to develop the assessment was proposed by R. Mislevy. It is called Evidence Centered Design (ECD) $[16,17]$. ECD is based on the construction of the task proposed by S. Messik [18] and ideas of S Toulmin (Toulmin S. 1958) on the use of universal patterns [19]. Patterns represent a set of ready-made solutions to common problems, but they provide a general description of the solution to the problem so that the most successful of them can be used in similar situations multiple times. In other words, they give the developer the opportunity to solve the problem in the already known way. The algorithm of using the template provides the conjugation of the student's model (list of controlled elements) and a set of proofs which confirm the task success (criteria and evaluation scales) [20], the conjugation of completed tasks, the results of scaling and conclusions about the level of preparedness of the subjects on the basis of their scores [21, 22]. According to S. Messik, the important point in the preparatory process of assessment materials is the development of evaluative rubrics construct. Design patterns of verifiable achievements, psychometric models of estimated characteristics and types of tasks with a set of relevant tasks and processes of their implementation, methods of reliable argumentation of assessment are applicable to such evaluation model. Toulmin suggests the following elements of argumentation: claim, data, warrant, backing, rebuttal and qualifier. Backing in the form of control questions, survey results and other information reinforces the warrant for evaluation. Rebuttal as a counterargument points to the limitations of the claim. Qualifier represents a set of words (so, perhaps, because, if not, of course, presumably, always, etc.) limiting the claims and pointing to correctness criteria for the claims. One example of an argumentation pattern is shown in Fig. 2. 


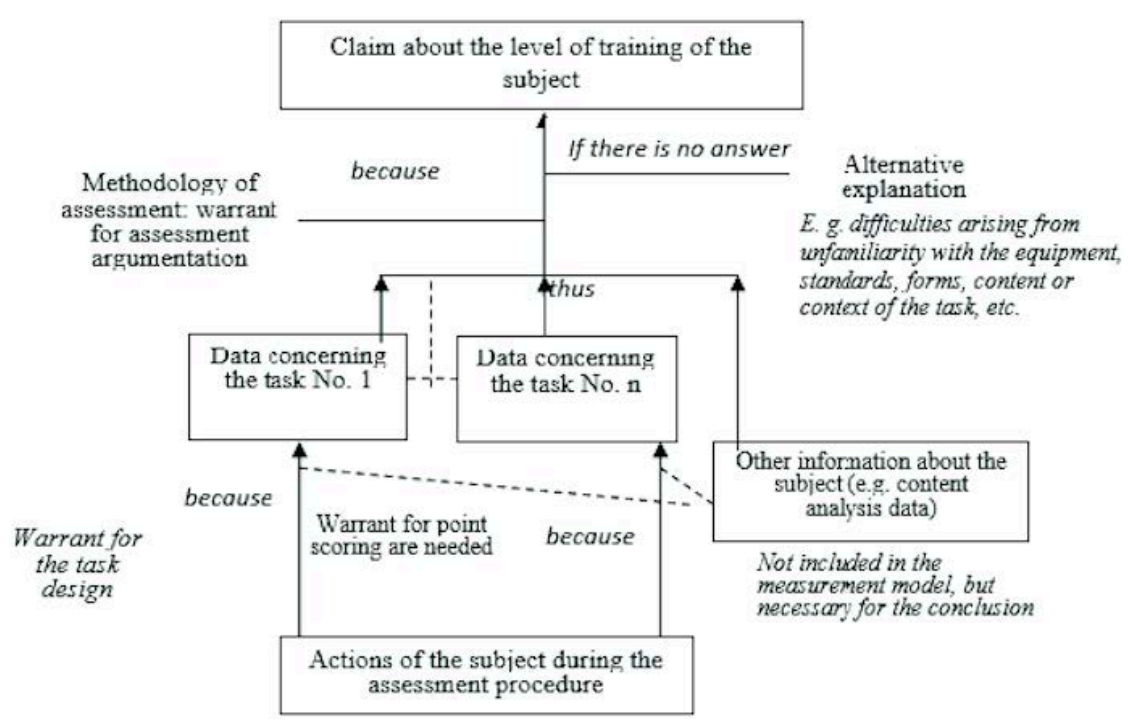

Fig. 2. The structure of the arguments in the ECD.

This scheme is the basis for planning the collection and analysis of arguments, the relationship between the actions of the subjects and the data obtained, as well as alternative explanations used as rebuttal or evidence. Assumptions and suppositions are necessary to infer how and why the statement is derived from the analysis of available data. Within ECD model the pattern-based assessment represents all the main processes of its development and implementation. The Evidence-Centered Design algorithm sets the design decisions for the allocation of the estimated characteristics of students, specification of the assessment tools, tasks and argumentation of the quality of their implementation, substantiation of the assessment on the basis of evidence, methods of presenting the output.

All stages of the assessment process development, from the operationalization of the tasks (form processing) and establishing the evaluation scale to the preparation of tasks and formulating the conditions for their implementation, should demonstrate that they, in fact, assess what they were supposed to, and the assessment shows what knowledge a test subject obtained. The ECD method can be successfully applied in the development of any assessment, both in the assessment of knowledge and in the assessment of competencies, where the a priori determination of structures and related variables of measurement make sense. It is important to ensure that the data would indicate preparedness of subjects only when their value for the final conclusion is clearly established.

The development of evidence-based modeling of evaluation tools expands the range of assessment obtained and increases their reliability. The evaluation mechanism based on the system of evidence (evidence and argumentation) consists of two parts: rules describing the notable features of the task answers and ways of adjustment for final assessment on the basis of contextual information of evidence and rebuttal of the observed features of the answer. Evidence-based assessment design allows us to understand how cognitive modeling of the assessment process and assessment materials contributes to the reliability of the results and their impact on learning motivation.

The theory of didactics still tries to find answers to numerous questions regarding assessment: when, at what stages of learning process, for what purposes, by means of what educational measurement and technologies, with what interpretation of results it is 
necessary and possible to perform an assessment, for what purposes testing is preferable, and for what purposes it is better to use traditional forms of control. But in any case, the most important result of an objective assessment, which determines the importance of control and evaluation systems and processes, is the creation of conditions for the transition from administration within knowledge monitoring to the development of self-government based on self-analysis of achievements.

\section{References}

1. H. Murray. Explorations in personality (Oxford Univ. Press, New York, 1938)

2. McClelland, Human Motivation (Piter Publ, Saint-Petersburg, 2007)

3. J. Adams, J. of Abnormal and Social Psych. 67. 422-436 (1963)

4. A. Anastasi, Psychological testing (Pedagogika Publ., Moscow, 1982)

5. B. Ananyev. Psuchology of educational assessment (Pedagogika Publ., Moscow, 1980)

6. B. Weiner, J. of Educ. Psych. 71 (1), 3-25 (1979)

7. B. Mandel, Invitation to discussion on the reasons for absenteeism. 103-117 (2004)

8. A. Markova, Formation of learning motivation in school age (Prosveshchenie Publ., Moscow, 1983)

9. E. Skinner, Perceived control: Motivation, coping, and development. Thought control of action (Hemisphere Publishing Corporation, London, 1992)

10. H. Heckhausen, Motivation and activity (Piter Publ., Saint-Petersburg, 2003)

11. V. Shadrikov, The development of junior schoolchildren in various educational systems (Logos Publ., Moscow, 2012)

12. J. Biggs, Teaching for Quality Learning at University Buckingham (The Society for Research into Higher Education and Open University Press, 2003)

13. N. Efremova, Pedagogika. 3, 47-52 (2018)

14. N. Efremova, The Unity of Science: International Scientific Periodical Journal, 4-1, $27-$ 30 (2016)

15. N. Efremova, Testing: the theory, development and use in the practice of the teacher (Natsionalnoye obrazovaniye Publ., Moscow, 2012)

16. R. Mislevy, R. Almond, J. Lukas. A brief introduction to Evidence-Centered Design. (ETS Research Report RR-03-16) (Educ.Testing Service, New York, 2003)

17. R. Mislevy, J. Behrens, K.K. Dicerbo, R Levy, Evidence-Centered Design, psychometrics. 4(1), 11-48 (2012)

18. S. Messick, Educ. Researcher, 32 (2), 13-23 (1994)

19. S. Toulmin, The uses of argument (Cambridge University Press, Cambridge, 1958)

20. N. Efremova, M. Seninets, American J. of Educ., 4 (2), 975-994 (2018)

21. The Uses of Argument by Stephen E. Toulmin (Cambridge, Univ. Press, Cambridge, 2003)

22. N. Efremova, American Journal of Educ. 4 (2), 1048-1065 (2018) 